\title{
Lymphadenectomy for Colon Cancer: Is There a Consensus?
}

\author{
Eddy Cotte, $\mathrm{MD}^{1,2}$ and Olivier Glehen, $\mathrm{MD}, \mathrm{PhD}^{1,2}$ \\ ${ }^{1}$ Department of Digestive Surgery, Centre Hospitalo-Universitaire Lyon Sud, Hospices civils de Lyon, Pierre-Bénite \\ Cedex, France; ${ }^{2}$ EA 3738, Université Claude Bernard Lyon, Faculté de Médecine Lyon Sud, BP 12, Lyon, France
}

In this issue of Annals of Surgical Oncology, Park et al. present an interesting study analyzing patterns of lymph node metastasis in patients with right-sided colon cancer. ${ }^{1}$ With a large cohort of 419 patients, they studied the distribution of lymph nodes metastasis along the different arteries of right and transverse colon according to the location of adenocarcinoma. For cancer located from cecum to hepatic flexure, they found lymph node metastasis along ileocolic artery, right colic artery, and middle colic artery. For proximal transverse colon cancer, no lymph node metastasis was found along ileocolic artery. On the basis of their results, they propose some guidelines for surgical resection of right-sided colon cancer: ileocecal resection for cecal cancer does not seem oncologically safe, and resection preserving ileocolic artery and ileocolic valve performed for transverse colon cancer seems reasonable.

The extent of colon resection is principally based on tumor location and lymphadenectomy sacrificing colic arteries. Distal margins are rarely a problem, which imposes an extension of colic resection. There is no consensus on the extent of lymphadenectomy for colon cancer, and in particular for transverse colon cancer. Anatomic variations in the distribution of the right-sided colic arteries make it hard to standardize lymphadenectomy. This lack of consensus is one of the reasons why transverse colon cancers were excluded from the prospective randomized trials that evaluated findings of cancer in laparoscopic colectomies. $^{2-5}$

Lymphadenectomy for colon cancer may have three interests: prognosis, cure, and a measure of quality of colon cancer care. The prognostic value of lymphadenectomy is

(C) Society of Surgical Oncology 2009

Published Online: 17 March 2009

O. Glehen, $\mathrm{MD}, \mathrm{PhD}$

e-mail: Olivier.glehen@chu-lyon.fr now clearly established. Lymph node staging has a direct impact on adjuvant therapy. Many studies have demonstrated an improvement of survival correlated with a higher number of nodes in lymphadenectomy. ${ }^{6-8}$ Chen et al., in their study based on a large cohort of 82,896 patients, reported a statistically significant improvement of 54 months for median survival with stage II disease if $>15$ nodes were removed, compared with those in whom $<7$ nodes were removed. ${ }^{7}$ This important difference can be explained by the better staging of disease. It was shown that the risk of understaging (and thus undertreatment) is approximately $10 \%$ if $<13$ nodes were removed. ${ }^{9}$ A higher median survival was also found for stage III disease. The same results were also observed in the Intergroup Trial INT-0089. ${ }^{8}$ Five-year overall survival increased from $67 \%$ to $90 \%$ for $\mathrm{N} 1$ disease (1 to 10 lymph nodes removed vs. $>40$ ), and from $51 \%$ to $71 \%$ for N2 disease (1 to 35 lymph nodes removed vs. $>35$ ). These differences were on par with or better than the best reported results for various adjuvant chemotherapies with even the newest combination adjuvant chemotherapy regimens.

These results suggest that extensive lymphadenectomy may have a curative value because stage migration cannot explain the results observed for $\mathrm{N} 2$ disease. The number of lymph nodes recovered from a patient with colon cancer has been identified as a potentially important measure of the quality of cancer care by many organizations, including the American College of Surgeons and the American Society of Clinical Oncology. Despite the previous results, there is still controversy over the importance of obtaining increased numbers of lymph nodes during colon cancer surgery. The International Union Against Cancer proposed a minimum of 12 lymph nodes. ${ }^{10}$ However, compliance with this guideline is poor. In the population-based study of Chen et al., in $<50 \%$ of right colon cancer cases and $<40 \%$ of transverse colon cancer cases, the number of lymph nodes removed was $>11 .^{7}$ A randomized, controlled trial 
would be necessary to definitively establish the minimum number of lymph nodes to be removed. This study is not possible until all of the determinants of lymph node numbers can be controlled.

As a result of the lack of evidence, and because of the limited morbidity of lymphadenectomy for right-sided colon cancer, extensive mesenteric lymphadenectomy should be considered.

\section{REFERENCES}

1. Park IA, Choi GS, Jun SH. Lymph node metastasis patterns in right-sided colon cancer: is segmental resection of these tumors oncologically safe? Ann Surg Oncol. (in press).

2. Clinical Outcomes of Surgical Therapy Study Group. A comparison of laparoscopically assisted and open colectomy for colon cancer. N Engl J Med. 2004;350:2050-9.

3. Guillou PJ, Quirke P, Thorpe H, et al. Short-term endpoints of conventional versus laparoscopic-assisted surgery in patients with colorectal cancer (MRC CLASICC trial): multicentre, randomised controlled trial. Lancet. 2005;365:1718-26.
4. Lacy AM, Garcia-Valdecasas JC, Delgado S, et al. Laparoscopyassisted colectomy versus open colectomy for treatment of nonmetastatic colon cancer: a randomised trial. Lancet. 2002;359: 2224-9.

5. Veldkamp R, Kuhry E, Hop WC, et al. Laparoscopic surgery versus open surgery for colon cancer: short-term outcomes of a randomised trial. Lancet Oncol. 2005;6:477-84.

6. Chang GJ, Rodriguez-Bigas MA, Skibber JM, Moyer VA: Lymph node evaluation and survival after curative resection of colon cancer: systematic review. J Natl Cancer Inst. 2007;99:433-41.

7. Chen SL, Bilchik AJ. More extensive nodal dissection improves survival for stages I to III of colon cancer: a population-based study. Ann Surg. 2006;244:602-10.

8. Le Voyer TE, Sigurdson ER, Hanlon AL, et al. Colon cancer survival is associated with increasing number of lymph nodes analyzed: a secondary survey of intergroup trial INT-0089. J Clin Oncol. 2003;21:2912-9.

9. Scott KW, Grace RH. Detection of lymph node metastases in colorectal carcinoma before and after fat clearance. Br J Surg. 1989;76:1165-7.

10. Sobin LH, Wittekind $\mathrm{CH}$. International Union Against Cancer (UICC). TNM classification of malignant tumors. 5th ed. New York: Wiley, 2002. 